Conclusions Hamstring strength endurance and fatigability were both justified as potential risk factors of re-injury and should be integral parts of future rehabilitation programmes and prognostic screening.

\section{HAOS OR CHAOS? THE PROGNOSTIC VALUE OF THE HAMSTRING OUTCOME SCORE (HAOS) TO PREDICT THE RISK OF HAMSTRING INJURY}

\begin{abstract}
${ }^{1}$ Sander van de Hoef, ${ }^{2}$ Michel S Brink, ${ }^{3}$ Nick van der Horst, ${ }^{4}$ Maarten van Smeden, ${ }^{1}$ Frank Backx. ${ }^{1}$ Utrecht University, University Medical Center, Division Brain, Department Rehabilitation, Physical Therapy Science and Sports, Utrecht, Netherlands; ${ }^{2}$ University of Groningen, University Medical Center Groningen, Center for Human Movement Sciences, Groningen, Netherlands; ${ }^{3}$ FIFA Medical Center, Royal Netherlands Football Association, Zeist, Netherlands; ${ }^{4}$ Leiden University Medical Center, Department of Clinical Epidemiology, Leiden, Netherlands
\end{abstract}

\subsection{6/bjsports-2021-IOC. 147}

Background Hamstring injury incidence remains high among male soccer players. One of the reasons is low adherence for effective hamstring injury prevention programs. Insight in injury risk can contribute to better adherence for injury prevention measures. The hamstring outcome score ( $\mathrm{HaOS})$ might provide an insight in injury risk.

Objective To determine the relation between the HaOS and both previous and new hamstring injuries in male amateur soccer players, and to determine the prognostic value of the $\mathrm{HaOS}$ to predict the risk of hamstring injuries.

Design Data was collected during a large cluster-RCT investigating a hamstring injury prevention program.

Setting This study was executed during one competition (2016-2017) in 32 first class amateur soccer teams.

Participants 400 adult male amateur soccer players started the study.

Assessment of risk factors The participants filled in a baselinequestionnaire consisting of injury history and the HaOS. During one full competition hamstring injuries were registered prospectively.

Main outcome measurements Previous hamstring injuries, new hamstring injuries and the $\mathrm{HaOS}$ (total score and subdomains) were considered in this study.

Results In 356 players, a significant relation was found between the $\mathrm{HaOS}$ (total score and all $\mathrm{HaOS}$ subdomain scores) and previous and new hamstring injury $(\mathrm{F}=17,4$; $\mathrm{p}<0.0001$ and $\mathrm{T}=3.59, \mathrm{p}=0.001$, respectively). This indicated that more hamstring injuries during the previous season was related to lower scores on the $\mathrm{HaOS}$ and lower $\mathrm{HaOS}$ scores correspond with more new hamstring injuries. With a cut-off score of $80 \%$ on the $\mathrm{HaOS}$, logistic regression models showed a probability of $11 \%, 18 \%$ and $28 \%$ on a new hamstring injury in players with 0,1 or 2 previous injuries, respectively.

Conclusion The HaOS is significantly associated with both previous and new hamstring injury and might be a useful tool to provide insight in players' hamstring injury risk when used in combination with injury history.

\section{ECCENTRIC HAMSTRING STRENGTH AND SPRINTING PERFORMANCE CHANGES DURING THE OFF-SEASON IN SPANISH FOOTBALLERS}

1,2,3,4 Jordi Vicens-Bordas, 2,3Ernest Esteve, ${ }^{5}$ Azahara Fort-Vanmeerhaeghe, ${ }^{1,3,6,7}$ Martí Casals, ${ }^{8}$ Thomas Bandholm, ${ }^{9}$ Lasse Ishoi, ${ }^{10}$ David Opar, ${ }^{11,12}$ Anthony Shield, ${ }^{8,9}$ Kristian Thorborg. ${ }^{~}$ Sport and Physical Activity Studies Centre (CEEAF), University of Vic Central University of Catalonia (UVic-UCC), Vic, Spain; ${ }^{2}$ Sportclinic. Physiotherapy and Sports Training Centre, Girona, Spain; ${ }^{3}$ School of Health and Sport Sciences (EUSES), Universitat de Girona, Salt, Spain; ${ }^{4}$ Department of Medical Sciences, Universitat de Girona, Girona, Spain; ${ }^{5}$ Department of Sports Sciences, Ramon Llull University, FPCEE and FCS Blanquerna, Barcelona, Spain; ${ }^{6}$ Sport Performance Analysis Research Group, University of Vic, Vic, Spain; ${ }^{7}$ Medical Department, Futbol Club Barcelona, Barça Innovation Hub, Barcelona, Spain; ${ }^{8}$ Physical Medicine and Rehabilitation Research - Copenhagen (PMR-C), Department of Physical and Occupational Therapy, Department of Orthopedic Surgery, Clinical Research Center, Amager-Hvidovre Hospital, Copenhagen University, Hvidovre, Denmark; ${ }^{9}$ Sports Orthopedic Research Center - Copenhagen (SORC-C), Department of Orthopedic Surgery, Copenhagen University Hospital, Hvidovre, Denmark; ${ }^{10}$ School of Behavioural and Health Sciences, Australian Catholic University, Melbourne, Australia; ${ }^{11}$ Faculty of Health, School of Exercise and Nutrition Science, Queensland University of Technology, Brisbane, Australia; ${ }^{12}$ Institute of Health and Biomedical Innovation, Queensland University of Technology, Brisbane, Australia

\subsection{6/bjsports-2021-IOC.148}

Background Low eccentric hamstring strength and sprinting performance are associated with hamstring injury (HI) in football; however, the off-season effects on both qualities are unknown.

Objective The aim of the study was to investigate eccentric hamstring strength and sprinting performance changes during the off-season period in football players.

Design Prospective cohort study.

Setting Semi-professional $\left(3^{\text {rd }}-4^{\text {th }}\right.$ tier $)$ and amateur $\left(5^{\text {th }}-8^{\text {th }}\right.$ tier $)$ Spanish footballers.

Patients (or Participants) Male footballers $(n=107)$ were contacted to participate. Seventy-four footballers ( $25 \pm 4$ years, $178.0 \pm 6.6 \mathrm{~cm}, 74.9 \pm 8.1 \mathrm{~kg}$ ) were included in final analyses.

Interventions (or Assessment of Risk Factors) Eccentric hamstring strength (Nordbord) and sprint performance $(30 \mathrm{~m}$ sprint and V-Cut test) were assessed at the beginning (May-June 2017) and end of the off-season (July-August 2017). Previous $\mathrm{HI}$, age and off-season length were considered the independent variables.

Main Outcome Measurements Eccentric hamstring strength $(\mathrm{N}$; $\left.\mathrm{N} \cdot \mathrm{kg}^{-1}\right)$, 30m sprint $(5-10 \mathrm{~m}$ splits (s)) and change-of-direction performance (s). All outcomes were proposed before any data collection. Data was analysed using paired t-tests and linear mixed models.

Results No changes in eccentric hamstring strength were found at follow-up. Large $(2 \%, \mathrm{~d}=0.96 ; \mathrm{p}<0.001)$ and small $(1 \%$, $\mathrm{d}=0.46 ; \mathrm{p}<0.001)$ decrements in performance were found for $30 \mathrm{~m}$ sprint and $10 \mathrm{~m}$ split time at follow-up, respectively. Previous HI, age or off-season length had no effect on any of the outcomes.

Conclusions Footballers showed no reduction in eccentric hamstring strength but impaired sprint performance after the offseason period, independent of age, previous $\mathrm{HI}$ and length of off-season. This may suggest the risk of sustaining a HI during the pre-season is lowered, as a result of decreased maximal 